NotAs DE LEITURA

Reading Notes 



\title{
NuMA CIRO, A PERSONA ${ }^{1}$ \\ Numa Ciro, the persona
}

\section{Santuza Cambraia Naves*}

O canto das sereias não se parece com os cantos de trabalho. Não serve para nada a não ser para o gozo.

NUMA CIRO

\section{RESUMO}

A construção da persona Numa Ciro através de performance, figurino, música e poesia. A continuidade entre palco e vida, entre persona e pessoa, entre noite e dia, na medida em que as atividades de Numa Ciro, a artista, se conectam com as da intelectual Maria do Socorro, psicanalista lacaniana e teórica da cultura.

Palavras-chave: Numa Ciro; persona; arte e vida.

\begin{abstract}
The construction of the persona of Numa Ciro through performance, apparel, music and poetry. Continuity between life onstage and offstage, between persona and person, between night and day, to the extent that the activities of Numa Ciro, the performer, are connected with those of Maria do Socorro, intellectual, Lacanian psychoanalyst and culture theorist.
\end{abstract}

Keywords: Numa Ciro; persona; art and life.

${ }^{1}$ Agradeço a Numa Ciro, de uma certa forma co-autora deste texto, a Kate Lyra e Ana Luiza Martins-Costa, que realizaram comigo a entrevista com a artista (em 12 de outubro de 2006), a Claudia Oliveira, por ter me estimulado a falar sobre Numa Ciro, a Antonio Herculano Lopes, por ter me auxiliado a pensar a performance, e particularmente a Paulo Henriques Britto, pela sua assessoria em questões de versificação, entre outras.

* Professora de antropologia do Departamento de Sociologia e Política da PUC-Rio e pesquisadora de música popular. 
Quando a conheci, Numa Ciro era concebida como uma figura de palco. Nos bastidores, voltava a ser Maria do Socorro, psicanalista lacaniana e teórica da cultura. Aos poucos, Numa Ciro passou a identificar tanto a persona quanto a pessoa, e só no mundo restrito da psicanálise se proferia o nome Maria do Socorro. Esta transição coincidiu com a sua atitude de jogar cada vez mais com a indefinição entre a persona e a pessoa, entre o palco e a vida. É bem verdade que as representações de Numa Ciro e Maria do Socorro já não se diferenciavam no início: ambas eram performáticas e não havia distinção entre elas com relação à maneira de se vestir e de se colocar no mundo, o que não causa espanto, se partimos do pressuposto de que a pessoa é também um artifício (MAUSS, 2003). A partir do momento, entretanto, em que a figura de Numa Ciro se tornou hegemônica, houve uma continuidade mais assumida entre arte e vida, entre noite e dia, pois as atividades de Numa Ciro, a artista, se conectaram de vez com as da intelectual Maria do Socorro. Este tipo de opção foi responsável pela guinada de Numa Ciro para uma carreira adicional na área de Letras.

Não me parece, entretanto, que a psicanalista Maria do Socorro se coloque num mundo à parte, alheia à realidade do espetáculo, ou que as figuras engendradas a partir dela se transformem em heterônimos, à maneira de Fernando Pessoa. O encontro da psicanalista com a performer é evidente, por exemplo, nas lembranças evocadas por ela das experiências de infância e adolescência, em que ajudava a mãe na costura. Sua mãe costurava, ela fazia o serviço de mão e as duas cantavam juntas enquanto trabalhavam. Assim, em entrevista concedida ao grupo de pesquisa do qual participo, afirma que já existia algo de Numa Ciro na "vivência desde criança de cantar em casa". Ela relata que, algum tempo atrás, lendo a biografia de Freud, soube que ele "adorava Yvette Gilbert, uma cantora parisiense amiga de Toulouse-Lautrec", e que Toulouse-Lautrec ia aos lugares onde ela se apresentava e a desenhava, imortalizando-a com as luvas pretas que vemos nas ilustrações. Ao ler a história de Yvette, descobre que "a mãe dela era costureira, que ela costurava junto com a mãe e que elas cantavam”.

Numa Ciro apresenta um perfil polissêmico, e não foi apenas Maria 
do Socorro que o inventou; trata-se de uma criação conjunta, com a participação do artista plástico Hildebrando, da compositora-cantora Tânia Chrystal, que lhe doou inclusive o nome, e do músico Flaviola. Tânia Chrystal, que dividia com ela um apartamento em Recife, inventou Numa Ciro para si própria, procurando articular um nome de mulher que jogasse ao mesmo tempo com o feminino e o masculino. Tânia não fez uso do nome, pois interrompeu por um tempo sua carreira musical e foi morar na Europa. Assim, numa das ligações telefônicas entre as duas amigas, Maria do Socorro pediu a Tânia que lhe cedesse o nome Numa Ciro, no que foi atendida.

Acompanhando a sua trajetória desde a década de 70 , vemos que Maria do Socorro alternava não só a moradia entre Campina Grande e Recife, como também os papéis de acadêmica - como professora de psicologia inicialmente na Universidade Estadual da Paraíba, e depois no Departamento de Educação da Universidade Federal da Paraíba - e de atriz de teatro. Iniciou sua carreira teatral em Campina Grande com o nome de Socorro Brito, na peça Quinze anos depois, de Bráulio Tavares, dirigida por Hermano José; em seguida, atuou no monólogo Fiel espelho meu, da dramaturga paraibana Lourdes Ramalho; e, por último, contracenou com Selma Tuareg na peça Escombros eletrônicos - um show de anormalidades. A partir dessas experiências teatrais, começou, em 1984, a assumir o palco como cantora e performer. A primeira apresentação foi no show Tangos e boleros punks, que fez com Diomedes no Bar Visual, em Campina Grande. No ano seguinte, sob a direção de Carlos Bartolomeu, fez o show Carta fatal no Teatro Paulo Pontes, em João Pessoa.

Fez sua estréia no Rio cantando "Surabaya Johnny", de Kurt Weil e Brecht $^{2}$, na Academia Brasileira de Letras. Ligada a um grupo de atores e poetas da chamada "Poesia pornô", do qual participavam, entre outros, Leila Miccolis e Caio Assis Trindade, participou do projeto que se chamou Alcova Brasileira de Letras, que realizou apresentações do grupo na ABL. Numa relata:

A Tânia Crystal veio para o Rio antes de mim e conheceu o Hildebrando. Ela falava dele para mim e dizia que ele é um

${ }^{2}$ Música da comédia musical Happy end, de Kurt Weill e Bertolt Brecht, de 1929. 
grande artista e que tem tudo a ver com a nossa cabeça, com a nossa vida e com as nossas coisas. Ela intuiu assim uma história entre eu e ele. E quando eu cheguei ao Rio em 85 ela nos apresentou e ficamos amigos. Em 86, quando me convidaram para fazer esta performance, nós resolvemos fazer juntos. E por acaso surgiu a história de ele me pintar nua e de eu cantar. A personagem, a persona Numa Ciro nasce ali, pois dali em diante ela tem corpo diferente e imagem diferente. Ela nasce mesmo sem ser nomeada ainda, mas é ali que está a Numa Ciro.

Eu chegava nua no palco, com um véu, ele botava o véu em mim.... Eu passava pasta d'água no corpo para dar uma tonalidade, uma transparência, para não ser carne mesmo. Ali ele me preparava como se eu fosse tela. Eu entrei no palco com o Austregésilo de Athayde na platéia assistindo. Tinha uns acadêmicos ao lado dele. O Hildebrando me pintou uma bomba atômica no corpo. Eu cantava "Surabaya Johnny" com o cabelo curto todo arrepiado, vermelho.

O primeiro contato com Numa Ciro me causou a impressão de que sua persona seria construída a partir de uma identidade gay, talvez pelo fato de tê-la visto compartilhar o palco do Sérgio Porto com travestis em algum momento do início dos anos 90. Por outro lado, tínhamos à época vários amigos gays em comum, e todos, sem exceção, a admiravam. Pensei logo em Susan Sontag (SONTAG, 1987) e sobre a possibilidade de Numa Ciro ser tomada, por um certo reduto gay do Rio de Janeiro, como uma espécie de ícone da sensibilidade camp, tal como Carmem Miranda foi incorporada por gays nova-iorquinos. À medida, porém, que fui acompanhando mais o seu trabalho, passei a reconsiderar a impressão inicial, ponderando que o entendimento da estética de Numa Ciro por critérios de opção sexual em muito estreitaria o seu alcance, principalmente se consideramos a maneira como ela lida com a diferença. As questões relativas às novas agendas políticas e culturais são contempladas por Numa Ciro ao realizar a sua proposta estética e construir a sua personalidade artística, já que o universo em que atua é singularizado pela presença de minorias tanto étnicas quanto sexuais. Mas ela não se prende a uma configuração específica, parecendo buscar, pelo contrário, elementos de diferentes repertórios, tanto os fornecidos por tradições locais, brasileiras ou estrangeiras, quanto os disponíveis por informações provenientes do mundo globalizado. 
Assim, observei que este procedimento de Numa Ciro de lidar tanto com o local quanto com o universal em muito evoca a estética da tropicália, no sentido de ter um pé em Campina Grande, sua cidade de origem, e outro tanto no mundo erudito da biblioteca de Borges quanto no submundo dos cabarés. A referência a Campina Grande não significa um apelo a regionalismos, até porque a cidade, tal como descrita por Numa, é ela própria uma junção de contrários, oscilando sempre entre o provinciano e o cosmopolita. É o que diz a letra de "A feira de Campina", canção que Numa fez em parceria com Hermeto Paschoal, em que artefatos artesanais e identificados com a cor local, como a "calunga de pano" e a "panela de barro", convivem com objetos modernos - e até mesmo fashion - legados pela tradição técnica ocidental:

\author{
Quero lhe mostrar nessa cantiga \\ foi na feira de Campina \\ onde o mundo se criou \\ Ouça com atenção na minha vida \\ não vi coisa mais divina \\ quando um cego anunciou \\ Quem se aventurar nesse mercado \\ deixe aqui o seu trocado \\ pelo nome de Jesus \\ Eu não tive a vossa alegria \\ de ganhar a luz do dia \\ A cegueira é minha luz \\ Quase num milagre a vista alcança \\ os detalhes de uma trança de cebola ou alfenim \\ Acocorando escolhe coisinhas de barro \\ só pensando na virtude desta mão que fez assim \\ No labirinto do roteiro encomendado \\ inverte a ordem do traçado \\ quem começa pelo fim \\ Corro na barraca de Zumira \\ vou buscar a lamparina \\ Severina encomendou \\ Olho para os lados, vejo briga \\ não é nada, é a pechincha \\ nada besta, o comprador \\ Quero visitar seu Aluísio
}


provar queijo de manteiga

apelidado de Romeu

Quando ele se junta com o doce

de goiaba, Julieta

mata quem disso comeu

Para comprar bode novo, tem lei

Pai-de-chiqueiro, cuidado! o cheiro

é desagradável demais porém

buxada é prato de rei

Pois é!

Dê outra volta pra gula vestir

carne de sol posta em mantas

e as lingüiças gravatas são fashion say

Luiz cantou isso outra vez

Calungas de pano

Panelas de barro

Jarrinhos de louça

Vestidos engomados

Pro recém-nascido touquinha e casaco

Pra quem gosta de cigano há quem leia o passado

Futuro é do tempo

Querer é de agora

Quem vem nessa feira vadia pela hora

Quem pega em rodilha não teme o balaio

Fumo de rolo e cachaça espanta o cansaço

O trocado pelo frete até logo obrigado

Olhe o porco

olhe o milho

Côco-catolé rosário pagão

Fuba de milho torrado, goma

Mandioca faz a farinha e mais

Pé-de-moleque beiju

Água de coco batiza o patrão

Quem diz que a fome não mata

bebe o sangue de quem planta arroz feijão

mexe a panela do angu

Não deixe a onda subir

Não deixe a feira acabar

Campina Grande é ali

Grande é a feira de lá

Irene num quadro a feira imortalizou

Irene não morre

É imortal quem pintou 
A canção programática "Meu nome é Numa Ciro", de sua autoria, que ela fez em "resposta" ao desafio "Meu nome é Trupizupe", de Bráulio Tavares, tem a forma do martelo agalopado, metro típico da poesia popular nordestina: versos decassílabos em que o acento recai sobre a terceira, sexta e décima sílabas. Vejamos a estrofe introdutória, em redondilha maior, na qual a autora se apresenta à maneira do repentista nordestino:

Meu nome é Numa Ciro
Sou a relva da campina
O meu nome é Numa Ciro
A providência divina

Em seguida, Numa Ciro introduz a primeira estrofe:

Com relação a questões propriamente temáticas, observamos que, na quinta estrofe, a imagem bucólica da "água que chove no roçado" convive com "o remédio que mata a bactéria", assim como a "rima das sextilhas" do cordel rima com "Alice no País das Maravilhas". Nas dez estrofes que compõem a letra, acompanha-se a tessitura da persona de Numa Ciro através de elementos díspares em franco diálogo, vinculados tanto à "tradição" quanto à "novidade". A estrofe número 9, por exemplo, comenta de maneira bem humorada a voga da internet:

Só se fala atualmente em internete Endereço eletrônico navegar Comunica quem aprende a sitiar Uma bomba que não mata mas impede A conversa cara a cara sem confete Pois eu acho esse papo muito sério 
Manuscrito vai perder o seu império

Sobre isto escrevi sem nostalgia

Pra não ter nem atraso de um dia

Eu mandei-o para Bráulio por é-méio

A última estrofe (número 10) revela a identidade constituída por elementos da "alta" e "baixa" cultura, do erudito e do pop:

\author{
Aprendi com minha avó quando menina \\ A fazer da cantoria vocação \\ Assistindo ao "Retalhos do Sertão" \\ Na rádio Borborema de Campina \\ Zé Limeira confirmou a minha sina \\ James Joyce com Homero foi casado \\ Guimarães flor Lispector encantado \\ Eu não posso viver sem escritura \\ Se transforma o criador em criatura \\ Quando eu canto martelo agalopado.
}

Assim, a Campina Grande representada por Numa Ciro lembra a interpretação do Brasil feita por Oswald de Andrade no "Manifesto da Poesia Pau-Brasil”, em que o que há de mais associado às raízes, como as cantigas de ninar, se adiciona ao "melhor de nossa demonstração moderna", do jornal aos "cubos de arranha-céus" (ANDRADE, 1972). Mas nos dois casos - a Campina Grande de Numa Ciro e o Brasil de Oswald de Andrade - não se articula uma síntese harmoniosa; porém, mantêm-se os elementos antinômicos em constante tensão. Os elementos da cidade vinculados a uma certa tradição do que reconhecemos como "nordestina", e mesmo "patriarcal”, são arrolados por Numa: do colégio de freira, onde estudara e onde "tudo era proibido", despertando o desejo de lidar com o que era interditado, aos bordados extremamente trabalhados que aprendera com a mãe. Já as contribuições da cultura pop internacional aparecem num primeiro momento com as revistas em quadrinhos, principalmente as fotonovelas. Citando trecho da canção "Livros", de Caetano Veloso "Tropeçavas nos astros desastrada/ quase não tínhamos livros em casa/ E a cidade não tinha livraria" ${ }^{3}$ - Numa Ciro relata que teve o primeiro contato

${ }^{3}$ CD Livro. Polygram. 1997. 
com a literatura - Ana Karenina, Pimpinela Escarlate, O corcunda de Notre Dame, A dama das camélias, Hamlet - através de fotonovelas. E refere-se também ao cinema, que aprendera a cultuar com uma tia, principalmente os filmes italianos com Sofia Loren e Gina Lollobrigida.

Como compositora (letrista), Numa Ciro fez diversas parcerias com Flaviola, e algumas com Hermeto Paschoal e Tânia Chrystal. Quando traduz, recria o texto original. Vejamos como ela própria discorre sobre este procedimento na seção 9 de "O canto a voz a palavra: anotações sobre a arte de dizer cantando":

Adoro fazer versões. Tanto para canções apenas instrumentais, como para aquelas que já possuem letras, na minha própria e em outra língua qualquer. Por exemplo: Replicante ("One More Kiss, Dear"), de Vangelis, do filme Blade Runner; "Libertango" de Piazzolla; "Numa Serenata" de Luiz Gonzaga. Faço um sampler, de trechos ou da música total. Gravo a base do disco original e canto por cima da base, nas performances e nos espetáculos. Algumas vezes mantenho na base a voz de um cantor cantando na língua original. Canto por cima e com isso descobri efeitos intertextuais muito interessantes.

Como intérprete, recorre a repertórios de poetas modernistas, nordestinos, dramaturgos e músicos contemporâneos, conseguindo sempre promover a conciliação de contrários, como a poesia de cordel de Bráulio Tavares com trechos de Ulisses, de James Joyce. No texto citado acima, Numa Ciro também fala sobre as suas escolhas:

Minha pesquisa abrange todo e qualquer gênero musical. Do repente ao rap, da valsa ao rock, do blues ao frevo, e por aí afora, estabelecendo uma relação entre o cancioneiro popular brasileiro e o estrangeiro, o popular e o erudito, criando com isso um mosaico provocador e universal. Além de meus próprios textos, trabalho com os textos de autores da literatura, entre os quais James Joyce, Guimarães Rosa, Ionesco; da poesia, João Cabral, Tavinho Teixeira, Haroldo e Augusto de Campos, Augusto dos Anjos, Neide Archanjo, e muitos mais. Já incluí em meu repertório um trecho do livro As palavras e as coisas de Michel Foucault (aquele em que o autor descreve o quadro As meninas, de velázquez). 
É interessante observar a maneira como Numa Ciro, ao se constituir como persona, faz uso dessas informações contrastantes, procurando, como no processo criativo de uma colagem, dispor os elementos díspares a partir de uma determinada concepção. No caso, o ponto articulador seria a noção de "periferia" que, para Numa Ciro, significaria tudo aquilo que ela via, ao longo de sua experiência, como excluído do modelo cultural dominante, como a ambiência dos cabarés e as mulheres que os frequentavam, e o espaço reservado às empregadas domésticas dentro das casas e da hierarquia social. Assim, a sensibilidade tropicalista é revisitada através da união de contrários, porém atualizada, ao escolher os repertórios a serem incorporados, dos locais aos universais. Por exemplo, um dos ingredientes dominantes, a tradição estrangeira da chanson, principalmente a do cabaré alemão, mostra-se em constante diálogo com a folclórica e com o pop que chega a Campina Grande em forma de kitsch.

Trata-se, sem dúvida, de lidar com a tradição kitsch do melodramático, mas de uma maneira estilizada, recorrendo a recursos que lembram o expressionismo alemão. Numa Ciro, no palco, depura o teor dramático das canções. O uso da máscara e do figurino contribui para o efeito de distanciamento, o que também sugere uma apropriação da proposta dramatúrgica de Bertolt Brecht. Como vemos, tudo parece dialogar com a tradição alemã. O rosto, sempre pintado de branco, faz ressaltar os olhos coloridos e redesenhados em preto. E o semblante criado no palco afasta qualquer possibilidade de representação naturalista; tudo é artifício, tudo é representação teatral. Por outro lado, a adoção do estilo cool não lhe retira o senso de humor: Numa Ciro reúne o melodrama pop, o teatro alemão (o expressionista, o brechtiano e o esquete popularesco de cabaré) e a carnavalização tropicalista. Neste aspecto, tudo indica que há um traço camp em Numa Ciro, principalmente se tomarmos em consideração a sua atitude de lidar ironicamente com o kitsch. Mesmo porque a sensibilidade camp, detectada por sontag no meio de certas "igrejinhas" culturais - e homossexuais - de Nova Iorque, seria fundamentalmente antitrágica, anti séria e jocosa. Uma postura reveladora desse tipo de atitude seria uma incorporação divertida do kitsch, como, por exemplo, através do ato de deixar 
à mostra, na sala de visitas, um artefato "típico" do Rio de Janeiro vendido em loja para turistas. O camp, aliás, só se realiza, segundo Sontag, com a incorporação do kitsch (SONTAG, 1987:318/33).

Retomo aqui o argumento que deu início a este ensaio: ao incorporar a intelectual Maria do Socorro à sua persona, Numa Ciro promoveu uma junção definitiva entre arte e vida, entre palco e cotidiano. A atitude performática de Numa Ciro traz à baila alguns questionamentos sobre o estatuto da obra de arte e do próprio artista que muitos classificariam como "pós-modernos". Se não é possível, para os que comungam desse ponto de vista, pensar um espetáculo artístico que se pretenda só musical, ou teatral, ou mesmo visual, ou que não vislumbre a participação do espectador como co-autor, e não apenas como fruidor, também não seria possível pensar a presença do artista no palco a não ser como não presença, ou seja, como não autor, como uma persona que se constrói recorrendo a diversos textos de diferentes vozes (ver LOPES 2003). Creio que é mais razoável vê-la como uma artista numa acepção mais ampla, uma performance artist na tradição inventada por figuras que, como Laurie Anderson, romperam com o enquadramento convencional do palco. No palco, Laurie Anderson, embora se apresente como tal, e embora muitas de suas canções e falações sejam na primeira pessoa, nunca é exatamente Laurie Anderson: está claro que boa parte do que ele conta e canta é fictício, e a voz que ouvimos é com freqüência distorcida ou engrossada eletronicamente; em última análise, sua performance ao vivo não é exatamente ao vivo, já que alguns dos sons que a plateia ouve foram previamente gravados ou preparados. Assim, algumas distinções categóricas - entre realidade e ficção, presença e ausência, autêntico e fingido - são desmontadas durante seus espetáculos.

Numa Ciro apresenta uma identidade múltipla, o que torna difícil defini-la. Sua atuação não se restringe à atividade de intérprete, ou mesmo de compositora, principalmente porque ela faz uso da performance. O corpo atua como escrita, como linguagem; assim, sua persona se constrói através do figurino, da música, da encenação e da poesia, como ela explica em "O canto a voz a palavra": 
o monólogo cantante ou o solo cantátil é um espetáculo de canto a capella, isto é, sem acompanhamento instrumental, onde a voz é o principal elemento de sustentação do espetáculo, concretizando uma linguagem cênico-musical em que são incorporados elementos do teatro, da dança, das artes plásticas, da poesia e da literatura.

A partir do canto, a criação dramática busca uma expressividade que os elementos interpretativos fundamentam. Assim, o diálogo entre o roteiro musical e a encenação transforma cada canção, cada texto ou poema numa composição de quadros que se sucedem no desenhar dos gestos e intenções.

E paradoxalmente - o que faz o encontro entre a psicanalista (não por acaso lacaniana) Maria do Socorro e a performer Numa Ciro atingir o paroxismo - a figura construída põe-se a desconstruir uma possível identidade fixa e a própria noção de autoria. Este procedimento é claro em "Meu nome é Numa Ciro", composição citada anteriormente. À maneira de Caetano Veloso, que responde à canção afirmativa de Gerônimo com relação à identidade étnica e sexual, "Eu sou negão", com "Eu sou neguinha?", canção que prima pela incerteza e pela indefinição, Numa Ciro responde ao espírito intimidativo de "Meu nome é Trupizupe", de Bráulio Tavares, que prima pela caracterização forte do nordestino, com o aspecto indeterminado de uma paraibana cosmopolita. Esta atitude desconstrutiva é descrita de maneira programática em "O canto a voz a palavra: anotações sobre a arte de dizer cantando", quando Numa Ciro diz: "canto textos poéticos e literários, e declamo canções".

Numa Ciro me contou algo que lhe aconteceu em Paris há algum tempo. Estava numa livraria e foi abordada por uma francesa que lhe perguntou: "Você é espanhola?" Numa disse que não, que era brasileira. A interlocutora então lhe disse que ela parecia uma personagem de Almodóvar. Eu disse a Numa que discordava da francesa, pois, na minha opinião, ela teria semelhanças com o próprio Almodóvar, talvez pela prática recorrente de ambos - que alguns veriam como pós-moderna - em conciliar num projeto estético tradições diferentes e, à primeira vista, inconciliáveis. 


\section{REFERÊNCIAS}

ANDRADE, Oswald. Manifesto da poesia pau-brasil. In: Do Pau-Brasil à Antropofagia e às utopias — Obras completas-6. Rio de Janeiro: MEC/Civilização Brasileira, 1972, pp. 3-10.

CIRO, Numa. O canto a voz a palavra: anotações sobre a arte de dizer cantando. Mimeo. S/d.

LOPES, Alexandre Herculano. Performance e história (ou como a onça, de um salto, foi ao Rio do princípio de século e ainda voltou para contar a história). In: O Percevejo - Revista de Teatro, Crítica e Estética, ano 11, no 12, p. 5-16, UNIRIO: Rio de Janeiro, 2003.

MAUSS, Marcel. Uma categoria do espírito humano: a noção de pessoa [1938]. In: Sociologia e antropologia. São Paulo, Cosac \& Naify, 2003, p. 169-397.

SONTAG, Susan. Notas sobre o camp. In: Contra a interpretação. Porto Alegre, L\&PM, 1987.

Submetido em: 09/12/2011

Aceito em: 13/12/2011 
